\title{
A Comprehensive Review on Nutraceuticals
}

\author{
Dr.S.Ruby*, S.Prakash, V.Pradeep Kumar, T.Praveen Kumar, S.Prathab.
}

Department of Pharmaceutical Chemistry, Vinayaka Mission's College of Pharmacy, Vinayaka Mission's Research Foundation (Deemed to be University), Salem (D.T), Tamil Nadu (State), India.

*Corresponding author's E-mail: rojerprakash18@gmail.com, ruby.s5902@gmail.com

Received: 18-03-2021; Revised: 22-05-2021; Accepted: 30-05-2021; Published on: 15-06-2021.

\section{ABSTRACT}

Nutraceuticals have received considerable interest because of their presumed safety. Nutraceuticals are food or part of food that provides medical or health benefits including the prevention and/or treatment of a disease. These nutraceuticals help in combating some of the major health problems of the century such as obesity, cardiovascular diseases, cancer, osteoporosis, arthritis, diabetes, cholesterol etc. Nutraceutical has advantage over the medicine because they avoid side effect, have naturally dietary supplement, etc. Nutraceutical on the basis of their natural source, chemical grouping, categories into three key terms -nutrients, herbals, dietary supplements, etc. The most rapidly growing segments of the industry were dietary supplements (19.5 percent per year) and natural/herbal products (11.6 percent per year). Global nutraceutical market is estimated as USD 404.8billion by 2025. FDA regulated dietary supplements as foods to ensure that they were safe. In 2006, the Indian government passed Food Safety and Standard Act to regulate the nutraceutical industry. Herbal nutraceutical is used as a powerful instrument in maintaining health and to act against nutritionally induced acute and chronic diseases, thereby promoting optimal health, longevity, and quality of life. The Present article focuses on the need for adhere to the known healthy eating models, development of new nutraceuticals/functional foods/food supplements with novel health benefits, elucidation mechanisms of action of these products, to define the comprehensive aspects of nutraceutical. This article may act as a tool to abreast with the recent developments in nutraceutical research.

Keywords: Dietary supplements, Food supplements, Global market, Health problems, Nutraceuticals.

QUICK RESPONSE CODE $\rightarrow$

DOI:

10.47583/ijpsrr.2021.v68i02.021

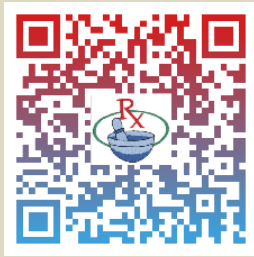

DOI link: http://dx.doi.org/10.47583/ijpsrr.2021.v68i02.021

\section{INTRODUCTION}

$\mathrm{N}$ utraceuticals is a term derived from "nutrition" and "pharmaceutics." The term is applied to products that are isolated from herbal products, dietary supplements (nutrients), specific diets, and processed foods such as cereals, soups, and beverages that other than nutrition are also used as medicine. Nutraceuticals are products, which other than nutrition are also used as medicine. A nutraceutical product may be defined as a substance, which has physiological benefit or provides protection against chronic disease. Nutraceuticals may be used to improve health, delay the aging process, prevent chronic diseases, increase life expectancy, or support the structure or function of the body. Nowadays, nutraceuticals have received considerable interest due to potential nutritional, safety and therapeutic effects. Recent studies have shown promising results for these compounds in various complications. In the present review much effort has been devoted to present new concepts about nutraceuticals based on their diseases modifying indications. Emphasis has been made to present herbal nutraceuticals effective on hard curative disorders related to oxidative stress including allergy, Alzheimer, cardiovascular, cancer, diabetes, eye, immune, inflammatory and Parkinson's diseases as well as obesity. The recently published papers about different aspects of nutraceuticals as alternative for pharmaceuticals were searched using scientific sites such as Medline, PubMed, and Google Scholar. The used terms included nutraceutical and allergy, Alzheimer, cardiovascular, cancer, diabetes, eye, immune, inflammatory or Parkinson. In the US, the term "nutraceutical" products are regulated as drugs, food ingredients and dietary supplements. Nutraceuticals, in contrast to pharmaceuticals, are substances, which usually have not patent protection. Both pharmaceutical and nutraceutical compounds might be used to cure or prevent diseases, but only pharmaceutical compounds have governmental sanction. A dietary supplement is considered as a product that bears or contains one or more of the following dietary ingredients: A mineral, a vitamin, an amino acid, a medical herb or other botanical, a dietary substance for use by man to supplement the diet by increasing the total daily intake, or a concentrate, metabolite, constituent, extract, or combinations of these ingredients. Nutraceuticals are of these nutritional supplements which are used for health purposes other than nutrition. Some popular nutraceuticals include ginseng, Echinacea, green tea, glucosamine, omega-3, lutein, folic acid, and cod liver oil. Majority of the 
nutraceuticals possess multiple therapeutic properties. Nowadays nutraceuticals have received considerable interest due to potential nutritional, safety and therapeutic effects. the global nutraceutical market size is estimated to reach a value of USD 722.49 billion by 2027, expanding at a Compound Annual Growth Rate of $8.3 \%$

between 2020-27. Other noteworthy geographic markets like Japan and Canada forecast each to grow at $3.4 \%$ and $5.7 \%$ respectively over the period 2020-2027. Recent studies have shown promising results for these compounds in various pathological complications such as diabetes, arthrosclerosis, cardiovascular diseases (CVDs), cancer and neurological disorders. These conditions involve many changes, including alterations redox state. Most of nutraceuticals have antioxidant activity with the ability to counteract this situation. Hence they are considered as healthy sources of health promotion, especially for prevention of life threatening diseases such as diabetes, infection, renal and gastrointestinal disorders.

\section{The Reasons for Shift Towards Nutraceuticals Are 5,6}

$\checkmark \quad$ Nutraceuticals cover most of the therapeutic areas, such as anti-arthritic, cold and cough, sleeping disorders, digestion and prevention of certain cancers, osteoporosis, blood pressure, cholesterol control, pain killers, depression and diabetes.

$\checkmark$ Dissatisfied with pharmaceutical agents in promoting health, are turning to nutraceuticals to improve their health and prevent chronic disease.

$\checkmark \quad$ Health care provider recognize the fact that our heavily processed food supply coming from crops grown with chemical fertilizers, pesticides, herbicides, and often genetically modified seeds, lacks sufficient nutrients necessary for optimum Health. $\checkmark \quad$ Nutraceuticals show an ample scope to flourish in future as therapeutic agents with preventive and curative properties.

$\checkmark \quad$ People who have chronic diseases and have found no solution in allopathic medicines.

$\checkmark \quad$ Nutraceuticals are quickly replacing pharmaceuticals in prevention and management of acute and chronic health problems.

$\checkmark \quad$ Economically challenged patients, People believing more in prevention than a cure.

$\checkmark \quad$ Increasing numbers of consumers, concerned about healthcare costs.

\section{CATEGORIZING NUTRACEUTICALS ${ }^{7,8}$}

They can be classified on the basis of their natural sources, pharmacological conditions, as well as chemical constitution of the products. Most often they are grouped in the following categories: dietary supplements, functional food, medicinal food, pharmaceuticals.

A dietary supplement represents a product that contains nutrients derived from food products, and is often concentrated in liquid, capsule, powder or pill form. Although dietary supplements are regulated by the FDA as foods, their regulation differs from drugs and other foods. The food sources used as nutraceuticals are all natural and can be categorized as

- $\quad$ Carbohydrates \& Fiber

- $\quad$ Fat \& Essential fatty acids

- $\quad$ Protein

- Vitamins

- $\quad$ Minerals like Macro minerals\& Trace minerals

- Water and Other nutrients like Antioxidants, Phytochemicals \& Intestinal bacterial flora Recombinant nutraceuticals.

\section{Categories Based on Foods Available in Market}

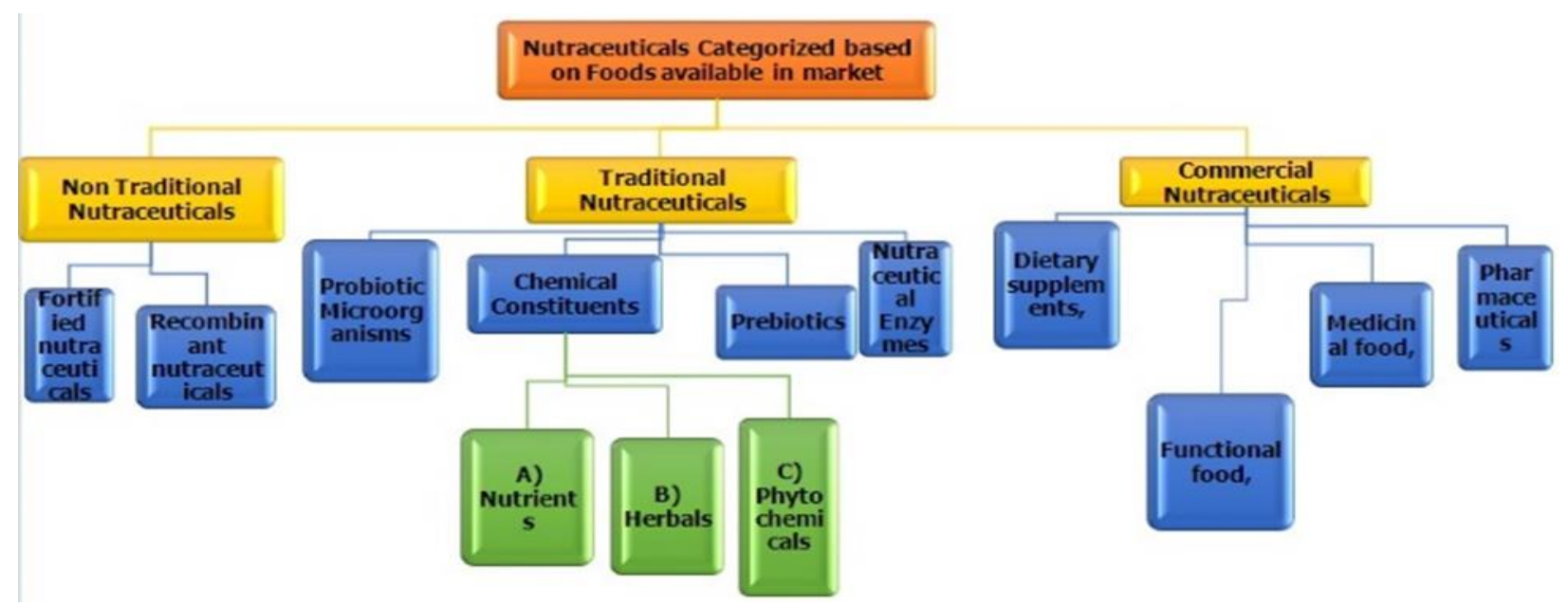

Figure 1: Categories based on foods available in market 


\section{NON-TRADITIONAL NUTRACEUTICALS ${ }^{9}$}

These Are artificial foods prepared with the help of biotechnology. Food samples contain bioactive components which are engineered to produce products for human- wellness.

They are arranged into two types:

\section{A. Fortified nutraceuticals. \\ B. Recombinant nutraceuticals.}

\section{A. Fortified nutraceuticals}

They are enriched with vitamins, minerals, usually at a range up to 100 percent of the Dietary Reference Intake for that nutrient. Fortified nutraceuticals are the food with agricultural breeding or with added nutrients. Some of the examples of fortified nutraceuticals are Orange juice with calcium, cereals with added vitamins or minerals, flour with added folic acid, and milk with cholecalciferol.

\section{B. Recombinant nutraceuticals}

Production of probiotics and the extraction of bioactive components by enzyme/fermentation technologies as well as genetic engineering technology are achieved through biotechnology. Energy-providing foods, such as bread, alcohol, fermented starch, yogurt, cheese, vinegar, and others are produced with the help of biotechnology.

\section{TRADITIONAL NUTRACEUTICALS ${ }^{10,11}$}

Traditional nutraceuticals are simply natural with no changes to the food. Food contains several natural components that deliver benefits beyond basic nutrition, such as lycopene in tomatoes, omega-3 fatty acid in salmon or saponins in soy.

\section{A. probiotic micro-organism}

B. prebiotics

C. chemical constituents

D. nutraceutical enzymes

\section{A. Probiotic Micro-organisms}

They act to crowd out pathogens, such as yeasts, other bacteria and viruses that may otherwise cause disease and develop a mutually advantageous symbiosis with the human gastrointestinal tract. They have an antimicrobial effect through modifying the microflora, preventing adhesion of pathogens to the intestinal epithelium, competing for nutrients necessary for pathogen survival, producing an antitoxin effect and reversing some of the consequences of infection on the intestinal epithelium, such as secretory changes and neutrophil migration. Probiotics can cure lactose intolerance by the production of the specific enzyme (ß-galactosidase) that can hydrolyse the offending lactose into its component sugars. Examples are Yogurt is one of the best sources of probiotics, which are friendly bacteria that can improve your health. Kefir is a fermented probiotic milk drink.

\section{B. Prebiotics}

"Prebiotics" are a more recent addition to our vocabulary and are substances which when consumed are not digested by us. Instead, they act as a nutrient source for the good probiotic bacteria. This encourages the probiotic bacteria to grow in a favourable environment, which in turn reduces the chances that harmful microorganisms may start to grow in our digestive tract.Example: Inulin is a prebiotic that has been widely used in processed foods. Essentially, It is a type of fiber obtained from the roots of plants such as chicory, Jerusalem artichoke, and even dandelions.

\section{Chemical Constituents}

\section{HERBAL}

Nutraceuticals holds a great promise to improve health and prevent chronic disease with the help of herbals. Some examples are Aloe Vera gel: Dilates capillaries, antiinflammatory, emollient, wound healing properties. Ephedra: Bronchodilator, vasoconstrictor, reduces bronchial Oedema. Garlic: Antibacterial, antifungal, antithrombotic, hypotensive anti-inflammatory Liquorice: Expectorant, secretolytic, treatment of peptic ulcer. Ginger: Carminative, antiemetic, cholagogue, positive inotropic.

\section{PHYTOCHEMICALS}

Phytochemicals basically is plant nutrients with particular biological activities in supporting human health and fight against many harmful diseases of the human beings. Examples are Carotenoids (isoprenoids) found in various fruits, vegetables and egg yolk are anti-carcinogenic, boost natural killer immune cells and protect cornea against UV light. Legumes (chickpeas and soybeans), grains, palm oil contain non-carotenoids, which remove cholesterol and are anti-carcinogenic. Sulphides, found in garlic and onions, may strengthen the immune system. Foods rich in phytochemicals include apples, apricots, broccoli, Brussels sprouts, cabbage, carrots, cauliflower, garlic, legumes, onions, red peppers, soybeans, sweet potatoes, and tomatoes.

\section{Nutraceutical Enzymes}

Enzymes are an essential part of life, without which our bodies would cease to function. Those people who are suffering from medical conditions such as hypoglycaemia, blood sugar disorders, digestive problems and obesity, eliminate the symptoms by enzyme supplements to their diet. These enzymes are derived from microbial, plant and animal sources. Examples are Xylanase enzyme is derived from Trichoderma sp. Benefits: Xylanase digests high molecular weight arabinoxylans and can be used in the treatment of endosperm cell walls of feed grains and vegetable proteins the addition of Xylanase to feed offers solutions to many problems associated with arabinoxylans. Papain enzyme is widely used in the Nutraceuticals industry as a protease enzyme to help protein digestion. They split the chains of proteins producing small peptides and eventually free the amino acids, which can be absorbed by the human body. Lactase enzyme is derived from 
Aspergillus sp. lactose (4-O- $\beta$-D galactopyranosyl-Dglucose) and produces $\beta$-D-galactose and $\alpha$-D glucose. Benefits: The use of Lactase increases digestive capacity. Lactase has optimum activity in an acidic environment, thus being effective in conditions encountered in the digestive tract of humans.

\section{COMMERCIAL NUTRACEUTICALS ${ }^{12,13}$}

New molecule is difficult to discover and more expensive and risky than ever before. Many pharmaceutical companies are now trying to manufacture nutraceutical because there is undoubtedly a very huge and growing market. Recognition of health benefits from consumption of omega-3 rich seafoods is one of the most promising developments in human nutrition and disease prevention research in the past three decades.

\section{A. Dietary supplements,}

\section{B. Functional food,}

\section{Medicinal food.}

\section{Pharmaceuticals.}

\section{A. Dietary supplements}

A dietary supplement is a product that contains nutrients derived from food products that are concentrated in liquid or capsule form. Dietary supplements, such as the vitamin B supplement are typically sold in pill form. In the US, the Dietary Supplement Health and Education Act (DSHEA) of 1994 defined the term: "A dietary supplement is a product taken by mouth that contains a "dietary ingredient" intended to supplement the diet. The "dietary ingredients" in these products may include: vitamins, minerals, herbs or other botanicals, amino acids, and substances such as enzymes, organ tissues, glandular, and metabolites. Dietary supplements can also be extracts or concentrates, and may be found in many forms such as tablets, capsules, soft gels, gel caps, liquids, or powders. Dietary supplements do not have to be approved by the U.S. Food and Drug Administration before marketing, but companies must register their manufacturing facilities with the FDA. With a few well-defined exceptions, dietary supplements may only be marketed to support the structure or function of the body, and may not claim to treat a disease or condition, and must include a label that says: "These statements have not been evaluated by the Food and Drug Administration. This product is not intended to diagnose, treat, cure, or prevent any disease." it achieves this goal by using efficacy of such nutraceuticals in detoxifying the body, avoiding vitamin and mineral deficiencies, and restoring healthy digestion and dietary habit. Dietary supplements come in a variety of forms, including tablets, capsules, gummies, and powders, as well as drinks and energy bars. Popular supplements include vitamins D and B12; minerals like calcium and iron; herbs such as echinacea and garlic; and products like glucosamine, probiotics, and fish oils.

\section{B. Functional foods}

Functional foods, according to their generally accepted definition, are "any food or food ingredient that may provide a health benefit beyond the traditional nutrients it contains". Functional foods are designed to allow consumers to eat enriched foods close to their natural state, rather than by taking dietary supplements manufactured in liquid or capsule form. Functional foods have been either enriched or fortified, a process called nutrification. This practice restores the nutrient content in a food back to similar levels from before the food was processed. Sometimes, additional complementary nutrients are added, such as vitamin D to milk. Health Canada defines functional foods as "ordinary food that has components or ingredients added to give it a specific medical or physiological benefit, other than a purely nutritional effect. In Japan, all functional foods must meet three established requirements: foods should be,

- $\quad$ Present in their naturally occurring form, rather than a capsule, tablet, or powder.

- $\quad$ Consumed in the diet as often as daily; and

- $\quad$ Should regulate a biological process in hopes of preventing or controlling disease.

Examples of functional foods are Fruits: berries, kiwi, pears, peaches, apples, oranges, bananas. Vegetables: broccoli, cauliflower, kale, spinach, zucchini. Nuts: almonds, cashews, pistachios, macadamia nuts, Brazil nuts. Seeds: chia seeds, flax seeds, hemp seeds, pumpkin seeds.

\section{Medicinal food}

Medicinal food plants may be defined as those food plants whose consumed parts receive recognition as therapeutic either in traditional medicine, ethnomedicine, or biomedicine. A holistic approach of the concept of medicinal foods was drawn from the study that foods are not intended to satisfy hunger and only provide essential macro and micronutrients to the body but also to supply it with bioactive ingredients that aid to decrease nutritionrelated diseases and ensure physical and mental well-being. In contrast, nutraceutical has been defined as "food or part of food that provide medical or health benefits, including the prevention and treatment of disease". The main difference is that nutraceuticals can be consumed in a nonfood matrix form as pills, capsules, or tablets, whereas functional or medicinal foods are taken as part of a normal food pattern. A food which is formulated to be consumed or administered internally under the supervision of a physician and which is intended for the specific dietary management of a disease or condition for which distinctive nutritional requirements, based on recognized scientific principles, are established by medical evaluation also without any components that promote disease condition or contain a specific nutrient that the body cannot normally produce due to specific disease condition. It is prescribed by physicians for various health conditions that lead to impaired ingestion, digestion, absorption, or metabolism of 
traditional foods like phenylketonuria, coeliac disease and lactose intolerance. Therefore, a medicinal food can be considered to position itself between traditional foods and pharmaceuticals, termed as the "Pharma-nutrition interface". "Let food be your medicine and medicine be your food." For example, spices which normally are used as flavour or taste enhancers in food were described as "influencers of body metabolism". Traditionally used in Indian cooking, turmeric (Curcuma longa) contains the active ingredient curcumin which is considered to have antioxidant, anti-inflammatory, and anticarcinogenic properties. Garlic (Allium sativum), which can be eaten raw or cooked, contains allicin. It has been documented to have LDL cholesterol lowering effects while increasing HDL levels, antihypertensive effects, and caused improved circulation. Peppermint (Mentha piperita) has long been used to treat digestive problems like bloating, abdominal distension, and difficulty in evacuation due to its smooth muscle relaxant effect. thyme (Thymus vulgaris) and sage (Salvia officinalis) of the Lamiaceae family were used to cure spasmodic gastric-intestinal complaints, cough, bronchitis, laryngitis, and tonsillitis and used as a vermifuge in ancient Egypt.

\section{Pharmaceuticals}

pharmaceuticals or drugs are especially formulated and developed to treat, cure, or prevent disease, which under normal conditions do not form part of our physiology. Also, the pharmaceuticals have higher potency or biological activity compared to the phytochemicals which are normally ingested in insignificant amounts in diet and exert physiological effects only after long term use.

\section{LIST OF COMMERCIAL NUTRACEUTICALS}

Table 1: List of commercial nutraceuticals

\begin{tabular}{|c|c|c|c|}
\hline Product & Source & Category & Company \\
\hline $\begin{array}{l}\text { Probiotic wraps \& } \\
\text { hummus }\end{array}$ & $\begin{array}{l}\text { Ganeden BC30 (bacillus } \\
\text { coagulants) }\end{array}$ & $\begin{array}{l}\text { Support immune function } \\
\text { and promote digestive } \\
\text { health }\end{array}$ & Mediterranean \\
\hline Vita kids bread & $\begin{array}{l}\text { Fortified with MEG-3 } \\
\text { (Maternally expressed 3) } \\
\text { brand omega-3 }\end{array}$ & $\begin{array}{l}\text { Omega-3 EPA/DHA, along } \\
\text { with folic acid, vitamin C } \\
\text { and D }\end{array}$ & Irish pride bakers \\
\hline Splenda essentials & Wheat breads & $\begin{array}{l}\text { Zero calorie sweetener } \\
\text { products }\end{array}$ & McNeil nutrition \\
\hline $\begin{array}{l}\text { Greensuperfoods } \\
\text { antioxidant \& greens } \\
\text { powder. }\end{array}$ & Rice, raspberry & $\begin{array}{l}\text { Defend against free } \\
\text { radicals, supports brain } \\
\text { function, immune system }\end{array}$ & Amazing grass \\
\hline Phenorex & Bitter orange & Burn fat & Gaspari nutrition \\
\hline Assure for heart \& energy & $\begin{array}{l}\text { Tangerine, kiwi, } \\
\text { strawberry, melon. }\end{array}$ & Heart rhythm & $\begin{array}{l}\text { Assure food \& beverage } \\
\text { company }\end{array}$ \\
\hline Vectomega & Salmon & $\begin{array}{l}\text { Enhancer absorption of } \\
\text { omega-3 }\end{array}$ & Europharma \\
\hline Brainshiner & $\begin{array}{l}\text { Ginkgo biloba, } \\
\text { Ginseng }\end{array}$ & $\begin{array}{l}\text { Increase memory } \\
\text { Retension }\end{array}$ & $\begin{array}{l}\text { Multifunction } \\
\text { supplements }\end{array}$ \\
\hline Fuze & Fruits & $\begin{array}{l}\text { Source of antioxidants } \\
\text { Vitamin } A, C \text {, and } E\end{array}$ & Whitestone \\
\hline $\begin{array}{l}\text { Collagen enhance } \\
\text { Chews }\end{array}$ & Red wine, from grapes & Age-defying propeties & Resvitale \\
\hline $\begin{array}{l}\text { Forgiven alcohol } \\
\text { Burner }\end{array}$ & Rhodiola rosea extract & $\begin{array}{l}\text { Breakdown alcohol } \\
\text { by-products }\end{array}$ & $\begin{array}{l}\text { Forgiven bottling } \\
\text { Group }\end{array}$ \\
\hline Fish oil plus & Salmon & Perfect brain food & Pacific health, Inc. \\
\hline $\begin{array}{l}\text { Daytime restore \& night } \\
\text { time repose }\end{array}$ & $\begin{array}{l}\text { Ginseng, ginkgo } \\
\text { Biloba, }\end{array}$ & Restful sleep & Xigo health \\
\hline Cognisure & $\begin{array}{l}\text { Proline-rich } \\
\text { Polypeptide complex }\end{array}$ & $\begin{array}{l}\text { Support healthy aging } \\
\text { of the brain, for } \\
\text { Alzheimer's disease }\end{array}$ & Metagenics \\
\hline $\begin{array}{l}\text { Rice protein } \\
\text { Concentrate }\end{array}$ & Brown rice & High-protein alternative & Jarrow formulas \\
\hline Trident vitality & Mint and white tea & Maintain tooth & Cadbury north America \\
\hline
\end{tabular}




\section{TOP 10 NUTRACEUTICAL PRODUCTS}

This industry is continuing to grow and expand as healthconscious customers look for ways to stay healthy and fit. Here, we've taken a closer look at the top 10 nutraceutical products on the market right now.

1. Liquid Prenatal Vitamins Liquids have become a hot commodity within the nutraceutical industry. Prenatal vitamins continue to be one of the top 10 nutraceutical products. Not only do they supply the body with sufficient energy levels, but they also maintain these energy levels before, during and after pregnancy.

2. Vitamin D3 is important for maintaining good health, development and maintenance of healthy bones and teeth. Some studies have shown the Vitamin D3 can also boost your immune system and put you in a good mood. Combining Vitamin D3 with calcium, a healthy diet, and regular exercise can reduce the risk of developing osteoporosis.

3. Garcinia Cambogia - Weight loss is a hot commodity in the health and fitness industry. As a result, it has pushed Garcinia Cambogia to the top of the nutraceutical product list. Garcinia Cambogia can help boost your metabolic rate, which will help you burn calories. In addition, it can help curb food cravings and increase your mood.

\section{NUTRACEUTICAL MARKET IN DIFFERENT COUNTRIES}

4. Raspberry Ketones - Another health supplement, raspberry ketones act as a thermogenic agent and work excellently as a fat-blocking agent.

5. Green Tea Supplements - There is an incredibly popular market for green tea supplements. In fact, green tea supplements have topped $\$ 135$ million in the nutraceuticals industry. Known as a powerful antioxidant, it's also a great alternative to coffee for a caffeine buzz.

6. Echinacea - it is used against many infections including UTI's, herpes, bloodstream infections, syphilis, and more. It is also used for skin problems like eczema, psoriasis, sunrelated skin damage, and bee stings.

7. Probiotics - it can help you maintain the good bacteria in your body. By supplementing your healthy diet with probiotics, it can help move food through your gut.

8. Omega 3 Fatty Acids - These essential fatty acids are necessary for human health, but the body can't make them. Omega-3 fatty acids reduce inflammation and may help lower the risk of chronic diseases such as heart disease, cancer, and arthritis.

9. Alpha-lipoic Acid - Alpha-lipoic acid is a naturally occurring fatty acid that has been used in alternative medicine as an aid in weight loss, treating diabetic nerve pain, healing wounds, lowering blood sugar, and treating rheumatoid arthritis.

10. Vitamin B12 - can help with one's metabolism and has been shown to increase energy levels.

\section{NUTRACEUTICAL PRODUCTS MARKET, BY REGION (USD BILLION)}

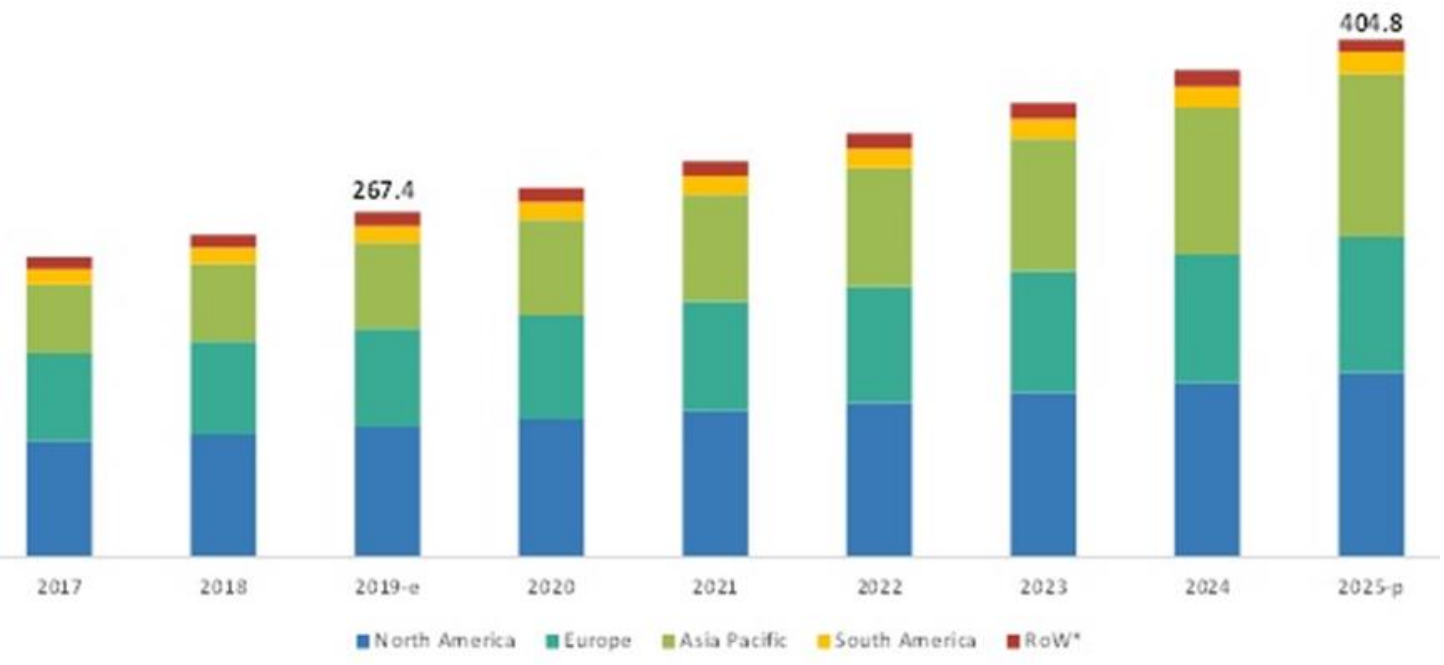

Figure 2: Nutraceutical market in different countries

The nutraceutical industry's three main segments include herbal/natural products, dietary supplements and functional foods. Among these, these most rapidly growing segments are the herbal/natural products and the dietary supplements. Research and development is at the peak in this emerging nutraceutical field. The greatest scientific need pertains to standardization of the nutraceutical compounds or products carefully develop and execute clinical studies to provide the basis for health claims to produce an impact on the consumers as well as on the nutraceutical companies. the Asia Pacific market is projected to record the fastest growth in the market. Factors such as busy lifestyles have led to an increase in the consumption of convenience food products. In addition, the 
rapid economic growth in countries of various regions has led to a surge in demand for fortified nutritional food \& beverage products in the region. The food \& beverage market in this region is currently undergoing a transformation due to rapid urbanization, diet diversification, and liberalization of foreign direct investment in the food sector. In addition, rising income, increasing purchasing power, and a surge in consumer demand for nutritional \& healthy products are factors projected to widen the growth prospects for manufacturers in the nutraceutical products market in the region.

Key Players of the World Market: Key vendors in the global market include Kraft Heinz Company (US), The Hain Celestial Group (US), Conagra (US), General Mills (US), Kellogg's (US), Nestlé (Switzerland), Nature's Bounty (US), Amway (US), Hero Group (US), Barilla Group (Italy), Raisio Group (Finland), Pfizer Inc (US), and Freedom Food Group Limited (Australia). These players have broad industry coverage and strong operational and financial strength; they have grown organically and inorganically in the recent past.

Key Players of the Indian Market: The Indian nutraceuticals market is dominated by pharmaceuticals and FMCG companies primarily with very few pure-play nutraceuticals companies. Some major companies marketing nutraceuticals in India are Dabur India, GlaxoSmithKline Consumer Healthcare, Cadila Healthcare, Zandu Pharmaceuticals, EID Parrys, Amway, Himalaya Herbal Healthcare, Sami Labs Ranbaxy and Elder Pharmaceuticals.

\section{Global Nutraceutical Products Market, by Region}

North America - U.S, Canada. Europe - Germany, U.K, France, Italy, Spain and Rest of Europe.

Asia Pacific - China, India, Japan, Australia, New Zealand and Rest of Asia Pacific.

Latin America - Brazil, Mexico, Rest of Latin America. Middle East \& Africa - GCC Countries, South Africa, Rest of Middle East \& Africa.

On the basis of type, the nutraceutical products market has been segmented as follows:

Food - Snacks, Confectionery products, Bakery products, Dairy products, Infant products

Beverages - Health drinks, Energy drinks, Juices. Dietary Supplements - Tablets, Liquid, Powder, Others (gummies, and chewable products)

On the basis of distribution channel, the market has been segmented as follows:

Conventional stores - Grocery stores, Mass merchandisers, Warehouse clubs, Online retailers.

Specialty stores - Bakery stores, Confectionery stores, Gourmet stores, Health centres.

\section{THE GROWING NUTRACEUTICALS MARKET IN INDIA}

Despite the foreign origins to the word 'Nutraceuticals', what it entails is indigenous to India. India has had a rich heritage of herbal medicines and supplements, which have found resonance in our mythology and folklore. The nutraceuticals market in India is expected to grow from $\$ 4$ billion in 2017 to $\$ 18$ billion in 2025 in the backdrop of rising demand for dietary supplements from upper and middle class. The nutraceuticals market in India can be further divided into functional food, beverages and dietary supplements. While functional food includes items such as breakfast cereals, and fortified flour, functional beverages include commodities like sports drinks, fortified juices, and glucose. Dietary supplements, which constitute over 65 percent of the Indian nutraceuticals market, include commodities such as macronutrients, herbal and nonherbal extracts. It is this segment that draws major competition and is the home ground to firms like Amway, Himalaya, Dabur and Emami. This segment is growing at a rate of 17 percent, and hence, will drive the growth of the market. Propelling the demand for nutraceuticals in India, among other factors, is the fact that 15 percent of the population is undernourished in the country, and the government has taken several measures to reduce the same through various initiatives such as Integrated Child Development Services (ICDS), National Health Mission (NHM) and the mid-day meal scheme. As per a World Bank report on 'Nutrition in India', India loses nearly US\$12 billion in Gross Domestic Product (GDP) to malnourishment. However, interventions to alleviate the loss would cost just about US\$ 524 million annually, thus, rendering a benefit-to-cost ratio of almost 23 times. This focus towards preventive care has also been accentuated due to the increasing costs of healthcare: 62 percent of the healthcare costs incurred in India are out-of-pocket expenditures.; 60 percent of medical prescriptions by doctors in India include supplements. Furthermore, India has also seen an increase in wealth as a result of which, its middle income and high-income households will drive nearly US\$ 4 trillion of the country's incremental consumption by 2030 . The strength of the Indian nutraceuticals market also emanates from certain supply drivers, which place it amongst the strongest markets in the world. Many of the supply drivers associated with the market are:

- Better GDP growth rate among the trillion-dollar economies;

- A large coastline spanning over 7,500 kms, with over 12 major and 200 minor ports make it an ideal manufacturing hub for the global value chain;

- India is home to largest number of US FDA approved plants located outside the US, a strong testament to its ability to line itself against global competitors;

- India has the lowest labour costs among South Asia and South East Asian Nations; 
- India has ample availability of ingredients - India is the world's second largest producer of fruits and vegetables, largest producer of milk and as of 2016, was the third largest market for active pharmaceutical ingredients;

- A significant increase in internet penetration has helped increase the availability and visibility of nutraceuticals in the market, due to which, by 2020 , nearly 40 percent of the total spend on FMCG in India will be influenced by digital media, a market opportunity of over US $\$ 45$ billion.

As nutraceuticals offer opportunities for pharmaceuticals companies to make their products more consumer-oriented, and for food producers to create brands with a medical image, this convergence of medicine, food and technology is further likely to provide impetus to the food processing industry and retail sector in India, which are slated to rise to over US\$958 billion by 2025 and US\$1.7 trillion by 2026, respectively. Further, the nutraceuticals sector has also been opened up significantly to attract foreign investments: 100 percent FDI is permitted in the manufacturing sector under automatic route, and such entities are allowed to sell their products through wholesale, retail or e-commerce; 100 percent investment is also allowed under automatic route for pharmaceutical entities under greenfield investments, while it is 74 percent for brownfield investments, with government approval required beyond 74 percent. Similarly, 100 percent FDI through government approval is allowed in food retailing with respect to food products manufactured in India. The growing demand for nutraceuticals has also helped give rise to ventures such as Health Kart, Patanjali, apart from creating room for further consolidation by global brands such as Cargill, Nestle, and Amway in the Indian market. Patanjali's stupendous performance of clocking over a billion dollars in revenue within a decade of its launch and the UK wellness giant, Holland \& Barrett entering the Indian market are further testament to the huge potential of the Indian nutraceuticals market.

\section{NUTRACEUTICALS AND DISEASES}

Nutraceuticals have been claimed to have a physiological benefit or provide protection against the following diseases such as: Cardiovascular, Diabetes, Obesity, Parkinson's Alzheimer's, Cancer, Allergy, Osteoarthritis, Eye disorders, Immune system and Inflammations.

\section{Cardiovascular disease ${ }^{14-21}$}

Cardiovascular diseases (CVD) is a chronic disease by means of disorders of the heart and blood vessels which generally include hypertension (high blood pressure), coronary heart disease (heart attack), cerebro-vascular disease (stroke), heart failure, peripheral vascular disease, etc. In cardiac heart disease, atherosclerotic plaques form on the inner surface of arteries, which narrow the lumen and reduced the blood flow. Further it would be the leading cause of death in developing countries. Majority of these diseases would be preventable and controllable. Nutraceuticals used in cardiovascular diseases are Anti-oxidants, Dietary fibres, Omega-3 poly unsaturated fatty acids, Vitamins, minerals for prevention and treatment of CVD. Milk and eggs having gamma linolenic acid (GLA) which has many benefits, including prevention and management of cardiovascular diseases. Polyphenols (in grape) prevent and control arterial diseases. Flavonoids (in onion, vegetables, grapes, red wine, apples, and cherries) block the ACE and strengthen the tiny capillaries that carry oxygen and essential nutrients to all cells.

\section{Diabetes ${ }^{22-28}$}

Diabetes mellitus is diseases caused due to abnormally high levels of blood glucose, either due to insufficient insulin production, or due to its ineffectiveness. There are two types of diabetes mellitus are type 1 diabetes (5\%), an autoimmune disorder, and type 2 diabetes (95\%), which is associated with obesity. Globally the total number of people with diabetes is projected to rise from 171 million in 2000 to 366 million in 2003. Diet therapy is the cornerstone for the management of gestational diabetes mellitus. Although there is widespread use of herbal dietary supplements that are believed to benefit type 2 diabetes mellitus, few have been proven to do so in properly designed randomized trials. Nutraceuticals used in diabetes are Lipoic acid, an antioxidant, for treatment of diabetic neuropathy. Ethyl esters of $n-3$ fatty acids may be beneficial in diabetic patients. Docosahexaenoic acid modulates insulin resistance and is also vital for neurovascular development. Dietary fibres from psyllium have been used for glucose control in diabetic patients and to reduce lipid levels in hyperlipidaemia. Herbal stimulants, such as ephedrine, caffeine, ma huang-guarana, chitosan and green tea help in body weight loss. People with diabetes are at higher risk of blood vessel damage from free radicals. Quercetin class of flavonoids called flavanols works as an antioxidant by scavenging damaging particles in the body known as free radicals.

\section{Obesity 29-31}

Obesity is now a global public health problem, defined as an unhealthy amount of body fat, which is responsible for many disorders like angina pectoris, congestive heart failure, hypertension, hyperlipidaemia, respiratory disorders, renal vein thrombosis, osteoarthritis, cancer, reduced fertility etc. The principal causes this rapid rise in obesity rates is the increased accessibility of high-fat, energy dense foods such as energy-rich foods (snacks, drinks, burger, pizzas etc) can encourage weight gain, which calls for a limit in the consumption of saturated and trans fats apart from sugars and salt in the diet about 315 million people are estimated to fall into the WHO-defined obesity categories. Nutraceutical interventions are currently being investigated on a large-scale basis as potential treatments for obesity and weight management. Nutraceuticals used in obesities are Buckwheat is a crop has special biological activities of cholesterol lowering effect, anti-hypertension effects and improving the constipation and obesity condition by acting similar as to dietary fibre present in food. 5-hydroxytryptophan and green tea extract may promote weight loss, while the former decreases appetite, 
the later increases the energy expenditure. Herbal stimulants, such as ephedrine, caffeine, ma huang-guarana, and green tea help in body weight loss. A blend of glucomannan, chitosan, fenugreek, G Silvestre, and vitamin $C$ in the dietary supplement significantly reduced body weight. Conjugated linoleic acid (CLA), capsaicin, Momordica Charantia (MC) possesses potential anti obese properties.

\section{Parkinson's disease ${ }^{32,33}$}

Parkinson's disease is defined as brain disorder or motor disorder that results from nerve damage in certain regions of the brain causing muscle rigidity, shaking, and difficult walking, usually occurring in mid to late adult life. Nutritional supplements have shown some promising results in preliminary studies, it is important to remember that there is not sufficient scientific data to recommend them for Parkinson's disease at present. Nutraceuticals used in Parkinson's diseases are some of these supplements have shown some promising results in preliminary studies. Vitamin E, glutathione, and creatine seem to be protective against Parkinson's disease. Creatine modifies Parkinson's disease features as measured by a decline in the clinical signs.

\section{Alzheimer's disease ${ }^{34-38}$}

Alzheimer's disease $(A D)$ is characterized by progressive dementia with memory loss as the major clinical symptom. Alzheimer's disease (AD) is the most common form of dementia. There is no cure for the disease and eventually leads to death. Most often, $A D$ is diagnosed in people over 65 years of age, although the less-prevalent early-onset Alzheimer's can occur much earlier. There were 26.6 million sufferers worldwide in 2006 and is predicted to affect 1 in 85 people globally by 2050 . Nutraceuticals used in Alzheimer's diseases are $\boldsymbol{\beta}$-Carotene, curcumin, lutein, lycopene, turmeric etc may exert positive effects on specific diseases by neutralizing the negative effects of oxidative stress, mitochondrial dysfunction, and various forms of neural degeneration.

\section{Cancer ${ }^{39-45}$}

Cancer has emerged as a major public health problem in developing countries. A high risk of cancer is associated with chronic inflammation risk. Chronic inflammation is also linked with immune suppression, which is a risk factor for cancer. At the molecular level, free radicals and aldehydes, produced during chronic inflammation, can induce deleterious gene mutation and posttranslational modifications of key cancer-related proteins. In year 2000, malignant tumours were responsible for 12 per cent of the nearly 56 million deaths worldwide from all causes. According to the World Cancer Report the cancer rates there would be 15 million new cases in the year 2020 i.e. a rise in $50 \%$. Nutraceuticals used in cancer are Lycopene concentrates in the skin, testes, adrenal and prostate where it protects against cancer. Lycopene is one of the major carotenoids in western diets and is found almost exclusively in tomatoes, water melon, guava, pink grapefruit and papaya. Phytochemicals derived from herbs and spices also have potential ant carcinogenic and anti-mutagenic activities, A broad range of "phytoestrogens" with a claimed hormonal activity, is recommended for prevention of prostate/breast cancer. Flavonoids found in citrus fruit appear to protect against cancer by acting as antioxidants Soy foods source of isoflavones, curcumin from curry and soya isoflavones possess cancer chemo preventive properties. Ellagic acid is a proven anti-carcinogen present in strawberries, cranberries and walnuts. Top of form Beet roots, cucumber fruits, spinach leaves, and turmeric rhizomes, were reported to possess anti-tumour activity Tannins present in blackberries, blueberries, cranberries, grapes, lentils, tea and wine with advantage to detoxify carcinogens and scavenge harmful free radicals. Curcumin (diferuloylmethane) which is a polyphenol of turmeric possesses anticarcinogenic, antioxidative and antiinflammatory properties. Pectin (apples) prevents prostate cancer by inhibiting cancer cells from adhering to other body cells.

\section{Allergy ${ }^{46-47}$}

Allergy is a hypersensitivity disorder of the immune system. An allergic reaction usually occurs when a person's immune system reacts to normally harmless substances. Allergic reactions are distinctive because of excessive activation of certain white blood cells called mast cells and basophils by a type of antibody called immunoglobulin $\mathrm{E}$. This reaction results in an inflammatory response which can range from uncomfortable to dangerous. Nutraceuticals used in allergy are Quercetin (QR) belongs to a group of polyphenolic substances known as flavonoids. Quercetin found in onions, red wine and green tea work as natural antihistamine and opposes the actions of the histamine in the body.

\section{Osteoarthritis}

Osteoarthritis is degenerative damage and loss of the articular cartilage of the joint due to loss of protein substance between the bones of joints. Osteoarthritis (OA), a debilitating joint disorder, is the most common form of arthritis in the United States, where it affects an estimated 21 million people. Joint disorders may reduce physical activity in individuals resulting in energy imbalance and weight gain. Nutraceuticals used in osteoarthritis are Glucosamine (GLN) and chondroitin sulphate (CS) are widely used to improve symptoms of osteoarthritis. Methyl sulfonyl Methane (MSM) used in combination with glucosamine and chondroitin for helping to treat or prevent osteoarthritis or joint disorder.

\section{Eye disorders ${ }^{48,49}$}

Healthy lifestyle with a diet containing foods rich in antioxidants, such as $n-3$ fatty acids, lutein and zeaxanthin appears beneficial for age-related macular degeneration (AMD). High content of polyphenolic flavonoids in nutraceuticals have been shown to possess antioxidant activity. Herbs or herbal extracts, such as green tea, Allium spp., Vitamins $\mathrm{C}$ and $\mathrm{E}$, polyphenols, carotenoids (mainly lycopene and $\beta$-carotene), and coenzyme Q10

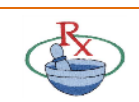


possess antioxidant properties and effective in AMD. Astaxanthin is an important naturally occurring carotenoid in the marine world such as sea bream, salmon, trout, and shrimps. It possesses a number of essential biological functions such as protecting against oxidation process, protecting against ultra violet light effects, immune response and pigmentation, in aquatic animals. It is also a very potent antioxidant. Astaxanthin offers powerful protection for the eyes and prevents macular degeneration. Astaxanthin protects heart from oxidative damage, protects the nervous system from degenerative diseases like AD and boosts immune system function. Lutein (found in mangoes, corn, sweet potatoes, carrots, squash, tomatoes and dark, leafy greens such as kale, collards and bok choy) also known as Helenian is used for the treatment of visual disorders. Zeaxanthin (found in corn, egg yolks and green vegetables and fruits, such as Broccoli, green beans, green peas, Brussel sprouts, cabbage, kale, collard greens, Spinach, lettuce, kiwi and honeydew) used in traditional Chinese Medicine mainly for the treatment of Visual Disorders.

\section{Immune system ${ }^{50,51}$}

A wide variety of nutraceuticals have been shown to impose crucial roles in immune status and susceptibility to some disease conditions. Nutraceuticals that belong to the category of immune boosters are useful to improve immune function. They include extracts from the coneflowers, or herbs of the genus Echinacea, such as Echinacea angustfolia, Echinacea pillida, Echinacea purpurea. The coneflowers in particular are a popular herbal remedy used in the central United States, an area to which they are indigenous. the Astragalus genus are also effective immune boosters. Astragalus stimulates development and transformation of stem cells in the marrow and lymph tissue to active immune cells. Phytoestrogens mostly are recommended for prevention of various diseases related to hormonal imbalance. There is a special interest in soy isoflavones as potential superior alternatives to the synthetic selective oestrogen receptor modulators, which are currently applied in hormone replacement therapy. Garlic and morphine also are good example of the nutraceuticals, which respectively stimulate and suppress immune system. The effect of herbal medicines and bacteria on the immune system and intestinal epithelial cell function has led to new credence for the use of nutraceuticals and probiotics in clinical settings. Probiotics are effective in conditions such as infectious diarrhoea in children and recurrent Clostridium difficile induced infections. Supplementation with probiotics (live viable microbial organisms) may provide maturational signals for the lymphoid tissue and improve the balance of pro and anti-inflammatory cytokines. Probiotics manipulate the intestinal microflora to maintain a normal balance between pathogenic and non-pathogenic bacteria. Usage of these agents in the treatment of specific diseases has evolved into the ability to very high index of safety, reduction of antibiotic use and the public's positive perception about "alternative" or "natural" therapies. Most probiotic preparations are comprised of one or more lactic acid bacteria. Within this group, strains of Lactobacillus, Bifidobacterium sp. and occasionally Streptococcus are most commonly used.

\section{Inflammation 52,55}

Inflammation is characterized by swelling, pain, redness and heat, and is the response of body tissues to irritation or injury. Nutraceuticals that their influence on osteoarthritis has been tested are ginger, soybean, unsaponifiable, glucosamine, chondroitin, S-adenosylmethionine. Although they are safe and well tolerated, however, the results are hampered by heterogeneity of the studies and inconsistent results. Vitamins $C$ and $D$ are micronutrients for which evidence of benefit exists. Cat's claw is a potent antiinflammatory agent. Scientists have attributed the efficacy of cat's claw to compounds called oxindole alkaloids; however, water-soluble cat's claw extracts that do not contain significant amounts of alkaloids do not possess strong antioxidant and anti-inflammatory effects. Resveratrol that is present in the fruits of Vaccinium myrtillus, Vaccinium angustifolium, Vaccinium ashei, and Vaccinium corymbosum shows the strongest sirtuinlike deacetylase action of any known phytochemical. Sirtuins are chemicals that inhibit cyclooxygenase- 1 enzyme and can extend the lifespan of yeast and fruit flies. They possess anti-inflammatory and antifungal activities. The omega- 3 and omega- 6 series have a significant role on diseases by generating potent modulatory molecules for inflammatory responses, including prostaglandins, leukotrienes, and interleukins. Gamma linolenic acid (GLA) is produced in the body from linoleic acid, an essential fatty acid of omega- 6 series. GLA is a nutraceutical used for treating problems with inflammation and autoimmune diseases. Preformed GLA is present in trace amounts in nuts, green leafy vegetables, vegetable oils, such as seed oil, borage oil, Oenothera biennis oil, blackcurrant and hemp seed oil. GLA is metabolized to dihomogamma linolenic acid which undergoes oxidative metabolism by lipoxygenase and cyclooxygenase enzymes to produce anti-inflammatory eicosanoids. Herbal nutraceuticals with anti-inflammatory activity are also available. Gentianine, present in Gentian root, is an effective anti-inflammatory agent. Bromo lain, a proteolytic enzyme found in extracts of stinging nettle, turmeric, pineapple, teas and extracts of turmeric or curcumin has anti-inflammatory activity. Osteoarthritis is a debilitating joint disorder which affects the number of populations. In 2004, the costs associated with all forms of arthritis were approximately 86 billion dollars. Joint discomfort from any joint disorders may reduce physical activity in subjects, resulting in energy imbalance and weight gain. Increased weight can exacerbate existing problems, through additional stress on joints. Glucosamine and chondroitin sulphate are widely used to alleviate symptoms of osteoarthritis. These nutraceuticals seem to regulate gene expression and synthesis of NO and PGE2, providing a plausible explanation for their antiinflammatory activities. 


\section{Miscellaneous complications of nutraceuticals 56,57}

Angiogenesis is an enzymatic process that is generally down-regulated in healthy individuals. Antiangiogenic compounds are selective against newly formed blood vessels while sparing existing ones may not lead to side effects even after prolonged exposure. Antiangiogenic compounds may prevent diseases involving degenerative process such as multiple sclerosis, arthritis, osteoporosis, diabetes, cancer, AD and Parkinson's diseases. Some bioactive compounds such as curcumin, flavins, isoflavones and catechins, resveratrol, proanthocyanin's, flavonoids, Saponins, terpenes, Chitin, chitosan, Vitamins B3 and D3, Fatty acids, peptides and amino acids are potentially effective angiogenic compounds. Moringa oleifera Lam has an impressive range of medicinal uses and is a good source various amino acid and phenolics, protein, vitamins, $\beta$ sitosterol, caffeoylquinic acid, kaempferol and $\beta$-carotene with high nutritional and therapeutic values. Various parts of this plant like leaves, seed, bark, fruit, roots, flowers and immature pods act as cardiac and circulatory stimulants, possess antitumor, antipyretic, antiepileptic, antiinflammatory, diuretic, antihypertensive, antidiabetic, cholesterol lowering, antiulcer, antispasmodic, antioxidant, hepatoprotective, antibacterial, and antifungal activities.

\section{Toxicity potential of nutraceuticals 58,59}

A large number of people believe that nutraceuticals, especially medicinal plants, are important remedies to address health issues with no side-effects. This belief has been raised from the fact that they have been used for a long period without serious toxicities. Although this is true for a wide variety of nutraceuticals and they generally have less side effects in comparison to pharmaceuticals, but conventional medicine is considered that if a drug is to be effective, inevitably, it will have toxic or side-effects. The medical establishment considers herbal medicines as drugs, and as such, they must have side effects. Therefore, they need to be prepared with correct ingredients and use with caution, too. People consume thousands of species of plants and other nutraceuticals to meet their basic nutritional needs, but only a limited number of them have received significant safety studies. Many remain poorly understood and largely undeveloped, and their wild relatives are threatened with extinction and in need of conservation attention. Stewardship of these valuable plant resources will require rigorous science combined with an approach that respects and values traditional knowledge systems.

\section{Anti-toxicity of nutraceuticals ${ }^{60-62}$}

Most of the synthetic drugs possess toxicity properties, and nutraceutical compounds, particularly herbal nutraceuticals have been investigated for their potential in combating the toxic effects of toxins and other medications. Although the toxicology of drugs is complex, there is great evidence for involvement of oxidative stress in the toxicity of a wide variety of drugs. Most of plants possess antioxidant activity and other than various specific ways to combat toxins and synthetic drugs, they generally may reduce their toxicity by reduction of oxidative stress. Kidney and liver are two organs which more than others are involved in toxic effects of other drugs as well as toxins. In this regard there are a wide variety of studies investigating the protective activities of nutraceuticals, especially medicinal plants against toxins and other drugs and promising results have been achieved.

\section{CONCLUSION}

Nutraceuticals are widely used in the food and pharmaceutical industries. Most of the nutraceuticals are from either mineral origin, animal origin or vegetable origin like gamma terpenes, beta carotene, curcumins, limonene, eugenol, pinene, safranal, geraniol, aloine, caryophyllene, lycopene and silymarin. These constituents are prepared into dosage forms as topical, oral, etc. viz. creams, lotions, ointments, emulsions, unani formulations, aromatic oils, microemulsions, SMEDDS, beads, tablets, emulgels, herbal formulations etc. used in various categories as antidiabetic, antibiotic, antimicrobial, anti-inflammatory, anti-cancer, protective, etc. Nutraceuticals are quickly replacing pharmaceuticals in prevention and management of acute and chronic health problems. Nutraceuticals show an ample scope to flourish in future as therapeutic agents with preventive and curative properties. Although nutraceuticals show a promising approach for the promotion of health and prevention of various diseases, yet health professionals, nutritionists, toxicologists should strategically work in collaboration to explore them for their full potential. A ray of cure preference in the mind of common patients revolve around nutraceuticals because of their false perception "All natural medicines are good". Also, a high cost of prescription pharmaceuticals and reluctance of some insurance companies to cover the cost of drugs help the nutraceuticals to solidify their presence in the global market of therapies and therapeutic agents. Use of nutraceuticals as an attempt to explore their therapeutic potential with minimum side effects as compared to conventional pharmaceuticals has observed a great success and met with huge monetary benefits. The preference for exploration and production of nutraceuticals over pharmaceuticals is evident in various pharmaceutical and biotechnology companies. Nutraceuticals still need extensive scientific research to prove their preference over pharmaceuticals. It can be achieved by enactment of FIM Proposed Nutraceutical Research and Education Act (NREA). It includes creation of a Nutraceutical Commission (NUCOM) specifically for the review and approval of nutraceuticals as well as clinical research. As per FIM, NREA should look into exclusive rights over the research and development. Cost wise of nutraceuticals should be kept within the accessibility of common man. There is an imperative need to focus on the establishments of new horizons in nutraceutical development.

\section{FUTURE PROSPECTS}

Nutraceuticals are products formed as a result of combined efforts of food, pharmaceutical and chemical industries. Botanical dietary supplement segment is anticipated to 
witness considerable growth over the forecast period of five years on account of increasing risk of various life style ailments like obesity, hypertension, diabetes etc. Rapidly expanding nutraceutical market is indicating the emergence of a new era in health and wellness industry. Inclination from Pharmaceuticals to nutraceuticals indicates the shifting trend in health care sector. Tremendous growth in nutraceutical industry has implications for food, pharmaceutical and agriculture sector. According to a latest research report by Grand View Research, nutraceutical market is projected to reach worth USD 578.23 Billion with CAGR of $8.8 \%$ by 2025 .

\section{REFERENCES}

1. Kalra EK, Nutraceutical - Definition and introduction. AAPS Pharm Sci. 2003;5:E25.

2. Chauhan B, Kumar G, Kalam N, Ansari SH, Current concepts and prospects of herbal nutraceutical: A review. J Adv Pharm Technol Res. 2013;4:4-8.

3. Zeisel SH, Regulation of "nutraceuticals" Science. 1999;285:1853-5.

4. Hardy G, Nutraceuticals and functional foods: Introduction and meaning. Nutrition. 2000;16:688-9.

5. Prevesh Kumar, Nirdesh Kumar and Tushar Omer, Nutraceuticalscritical supplement For building a healthy India, World Journal Of Pharmacy And Pharmaceutical Sciences, 2016; 5(3): 579-594.

6. Olaiya C. O, Soetan K. O, Esan A. The role of nutraceuticals, functional foods and value added food products in the prevention and treatment of chronic diseases M. 1, African Journal of Food Science, 2016; 10(10): 185-193.

7. Namdeo Shinde, Bhaskar Bangar, Sunil Deshmukh, Pratik Kumbhar Nutraceuticals: A Review on current status. Research J. Pharm. and Tech, 2014; 7(1): 110-113.

8. Kharb S, Singh V. Nutriceuticals in health and disease prevention Indian J. Clin. Biochem, 2004; 19(1): 50-53.

9. Jeroen Hugenholtz, Eddy J Smid, Victor Ladero, Pascal Hols. Metabolic engineering of lactic acid bacteria for the production of nutraceuticals. Antonie van Leeuwenhoek, 2002; 82: 217-235.

10. Vouloumanou EK, Makris GC, Karageorgopoulos DE. Probiotics for the prevention of respiratory tract infections: a systematic review. Int J Antimicrob Agents, 2009; 34:e1-e10.

11. Montrose DC, Floch $\mathrm{MH}$ : Probiotics used in human studies. J Clin Gastroenterol, 2005; 39(6): 469-484.

12. N Borkar, SS Saurabh, KS Rathore, A Pandit, KR Khandelwal; An Insight on Nutraceuticals; Pharma Tutor, 2015; 3(8): 13-23.

13. Enhancing Nutraceutical Performance Using Excipient Foods: Designing Food Structures and Compositions to Increase Bioavailability David Julian McClements, Liqiang Zou, Ruojie Zhang, Laura Salvia-Trujillo, Taha Kumosani, and Hang Xiao, Comprehensive Reviewsin Food Science and Food Safety, 2015; 14: 824-847.

14. Nasri H, Motamedi P, Dehghani N, Nasri P, Taheri Z, Kinani F, et al. Vitamin D and immune system. J Renal Endocrinol. 2014;1:5-7.

15. Asgary S, Kelishadi R, Rafieian-Kopaei M, Najafi S, Najafi M, Sahebkar A. Investigation of the lipid-modifying and antiinflammatory effects of Cornus mas L. supplementation on dyslipidemic children and adolescents. Pediatr Cardiol. 2013;34:1729-35.

16. Iriti M, Faoro F. Grape phytochemicals: A bouquet of old and new nutraceuticals for human health. Med Hypotheses. 2006;67:833-8.

17. Garg A, Garg S, Zaneveld $\sqcup$, Singla AK. Chemistry and pharmacology of the Citrus bioflavonoid hesperidin. Phytother Res. 2001;15:65569.
18. Rafieian-Kopaei M, Baradaran A, Rafieian M. Plants antioxidants: From laboratory to clinic. J Nephropathol. 2013;2:152-3.

19. Ghayur MN, Gilani AH, Afridi MB, Houghton PJ. Cardiovascular effects of ginger aqueous extract and its phenolic constituents are mediated through multiple pathways. Vascul Pharmacol. 2005;43:234-41.

20. Bahmani M, Vakili-Saatloo N, Gholami-Ahangaran M, Karamati SA, Khalil-Banihabib E, Hajigholizadeh $\mathrm{GH}$, et al. A comparison study on the anti-leech effects of onion (Allium cepa $\mathrm{L}$ ) and ginger (Zingiber officinale) with levamisole and triclabendazole.J HerbMed Pharmacol. 2013;2:1-3.

21. Nasri H, Nematbakhsh M, Ghobadi SH, Ansari R, Shahinfard N, Rafieian-kopaei M. Preventive and curative effects of ginger extract against histopathologic changes of gentamicin-Induced tubular toxicity in rats. Int J Prev Med. 2013;4:316-21

22. Bahmani M, Zargaran A, Rafieian-Kopaei M, Saki M. Ethnobotanical study of medicinal plants used in the management of diabetes mellitus in the Urmia, Northwest Iran. Asian Pac J Trop Med. 2014;7:348-54.

23. Roshan B, Stanton RC. A story of microalbuminuria and diabetic nephropathy. J Nephropathol. 2013;2:234-40.

24. Tavafi M. Diabetic nephropathy and antioxidants. J Nephropathol. 2013;2:20-7.

25. Baradaran A. Lipoprotein (a), type 2 diabetes and nephropathy; the mystery ontinues. J Nephropathol. 2012;1:126-9.

26. Rahimi-Madiseh M, Heidarian E, Rafieian-kopaei M. Biochemical components of Berberis lycium fruit and its effects on lipid profile in diabetic rats. J HerbMed Pharmacol. 2014;3:15-9.

27. Rafieian-Kopaei M, Nasri H. Ginger and diabetic nephropathy. J Renal Inj Prev. 2013;2:9-10.

28. Tolouian R, T Hernandez G. Prediction of diabetic nephropathy: The need for a sweet biomarker. J Nephropathol. 2013;2:4-5

29. Caterson ID, Gill TP. Obesity: Epidemiology and possible prevention. Best Pract Res Clin Endocrinol Metab. 2002;16:595-610.

30. Rubin SA, Levin ER. Clinical review 53: The endocrinology of vasoactive peptides: Synthesis to function.J Clin Endocrinol Metab. 1994;78:6-10.

31. Boozer CN, Nasser JA, Heymsfield SB, Wang V, Chen G, Solomon JL. An herbal supplement containing Ma Huang-Guarana for weight loss: A randomized, double-blind trial. Int J Obes Relat Metab Disord. 2001;25:316-24.

32. Losso JN. Targeting excessive angiogenesis with functional foods and nutraceuticals. Trends Food Sci Technol. 2003;14:455-68.

33. Anwar F, Latif S, Ashraf M, Gilani AH. Moringa oleifera: A food plant with multiple medicinal uses. Phytother Res. 2007;21:17-25.

34. Glenville M. Nutritional supplements in pregnancy: Commercial push or evidence based? Curr Opin Obstet Gynecol. 2006;18:642-7.

35. Brookmeyer R, Johnson E, Ziegler-Graham K, Arrighi HM. Forecasting the global burden of Alzheimer's disease. Alzheimers Dement. 2007;3:186-91.

36. Rabiei Z, Rafieian-Kopaei M, Heidarian E, Saghaei E, Mokhtari S. Effects of Zizyphus jujube extract on memory and learning impairment induced by bilateral electric lesions of the nucleus basalis of Meynert in rat. Neurochem Res. 2014;39:353-60.

37. Rabiei Z, Rafieian-kopaei M, Heidarian E, Saghaei E, Mokhtari S Effects of Zizyphus jujube extract on memory and learning impairment induced by bilateral electric lesions of the nucleus basalis of meynert in rat. Neurochem Res. 2014;39:353-60.4

38. Rabiei Z, Rafieian-Kopaei M, Mokhtari S, Alibabaei Z, Shahrani M. The effect of pretreatment with different doses of Lavandula officinalis ethanolic extract on memory, learning and nociception. Biomed Aging Pathol. 2013. 
39. Nasri H, Sahinfard N, Rafieian M, Rafieian S, Shirzad M, Rafieiankopaei M. Effects of Allium sativum on liver enzymes and atherosclerotic risk factors. J HerbMed.

40. Willis MS, Wians FH. The role of nutrition in preventing prostate cancer: A review of the proposed mechanism of action of various dietary substances. Clin Chim Acta. 2003;330:57-83.

41. Shirzad H, Kiani M, Shirzad M. Impacts of tomato extract on the mice fibrosarcoma cells. J HerbMed Pharmacol. 2013;2:13-6.

42. Stahl W, Sies H. Bioactivity and protective effects of natural carotenoids. Biochim Biophys Acta. 2005;1740:101-7.

43. Shirzad H, Taji F, Rafieian-Kopaei M. Correlation between antioxidant activity of garlic extracts and WEHI-164 fibrosarcoma tumor growth in BALB/c mice. J Med Food. 2011;14:969-74.

44. Shirzad H, Shahrani M, Rafieian-Kopaei M. Comparison of morphine and tramadol effects on phagocytic activity of mice peritoneal phagocytes in vivo. Int Immunopharmacol. 2009;9:968-70.

45. Limer JL, Speirs V. Phyto-oestrogens and breast cancer chemoprevention. Breast Cancer Res. 2004;6:119-27.

46. Grammatikos AP. The genetic and environmental basis of atopic diseases. Ann Med. 2008;40:482-95.

47. Kruger CL, Murphy M, DeFreitas Z, Pfannkuch F, Heimbach J. An innovative approach to the determination of safety for a dietary ingredient derived from a new source: Case study using a crystalline lutein product. Food Chem Toxicol. 2002;40:1535-49.

48. Chauhan B, Kumar G, Kalam N, Ansari SH. Current concepts and prospects of herbal nutraceutical: A review. J Adv Pharm Technol Res. 2013;4:4-8.

49. Brouns F. Soya isoflavones: A new and promising ingredient for the health foods sector. Food Res Int. 2002;35:187-93.

50. 53. Ardalan MR, Rafieian. Kopaei M. Antioxidant supplementation in hypertension. J Renal Inj Prev 2014;3:39-40.

51. Gupta P, Andrew H, Kirschner BS, Guandalini S. Is lactobacillus GG helpful in children with Crohn's disease? Results of a preliminary, open-label study. J Pediatr Gastroenterol Nutr. 2000;31:453-7.

52. Fuller R. Probiotics in human medicine. Gut. 1991;32:439-42.
53. Rafieian-Kopaei M. Identification of medicinal plants affecting on headaches and migraines in Lorestan Province, West of Iran. Asian Pac J Trop Med. 2014;7:376-9.

54. Jang M, Cai L, Udeani GO, Slowing KV, Thomas CF, Beecher CW, et al. Cancer chemopreventive activity of resveratrol, a natural product derived from grapes. Science. 1997;275:218-20.

55. Rouhi-Broujeni A, Heidarian E, Darvishzadeh-Boroojeni P, RafieianKopaei M, Gharipour M. Lipid lowering activity of moringa pergerina seeds in rat: A comparison between the extract and atorvastatin. Res J Biol Sci. 2013;8:150-4.

56. Nasri H, Ardalan MR, Rafieian-Kopaei R. On the occasion of world hypertension day 2014. J Parathyr Dis. 2014;2:19-20.

57. Baradaran A, Madihi $Y$, Merrikhi A, Rafieian-Kopaei $M$, Nematbakhsh M, Asgari A, et al. Nephrotoxicity of hydroalcoholic extract of Teucrium polium in Wistar rats. Pak J Med Sci. 2013;29:329-33.

58. Ateyyat MA, Al-Mazra'awi M, Abu-Rjai T, Shatnawi MA. Aqueous extracts of some medicinal plants are as toxic as Imidacloprid to the sweet potato whitefly, Bemisia tabaci. J Insect Sci. 2009;9:15.

59. Baradaran A. Beyond mineral metabolism, the bright immunomodulatory effect of vitamin $D$ in renal disease. $J$ Nephropharmacol. 2012;1:17-8.

60. Nasri H, Behradmanesh S, Ahmadi A, Rafieian-Kopaei M. Impact of oral vitamin $D$ (cholecalciferol) replacement therapy on blood pressure in type 2 diabetes patients; a randomized, double-blind, placebo controlled clinical trial. J Nephropathol. 2014;3:29-33.

61. Nasri H, Shirzad H. Toxicity and safety of medicinal plants. J HerbMed Plarmacol. 2013;2:21-2.

62. Heidarian E, Rafieian-Kopaei M. Protective effect of artichoke (Cynara scolymus) leaf extract against lead toxicity in rat. Pharm Biol. 2013;51:1104-9.

63. Nasri H, Ahmadi A, Baradaran A, Nasri P, Hajian S, Pour-Arian A, et al. A biochemical study on ameliorative effect of green tea (Camellia sinensis) extract against contrast media induced acute kidney injury. J Renal Inj Prev. 2014;3:47-9.

Source of Support: The author(s) received no financial support for the research, authorship, and/or publication of this article.

Conflict of Interest: The author(s) declared no potential conflicts of interest with respect to the research, authorship, and/or publication of this article.

For any question relates to this article, please reach us at: editor@globalresearchonline.net New manuscripts for publication can be submitted at: submit@globalresearchonline.net and submit_ijpsrr@rediffmail.com 